\title{
Aerosol Particles from Dried Salt-Lakes and Saline Soils Carried on Dust Storms over Beijing
}

\author{
Xingying Zhang ${ }^{1,2,3}$, Guoshun Zhuang ${ }^{1, *}$, Hui Yuan ${ }^{4}$, Kenneth A. Rahn ${ }^{5}$, \\ Zifa Wang ${ }^{3}$, and Zisheng $\mathrm{An}^{1,6}$ \\ ${ }^{1}$ Center for Atmospheric Chemistry Study, Department of Environmental Science and Engineering, Fudan University, \\ Shanghai 200433, China \\ ${ }^{2}$ Key Laboratory of Radiometric Calibration and Validation for Environmental Satellites, China Meteorological Administration \\ (LRCVES/CMA), National Satellite Meteorological Center, China Meteorological Administration, Beijing 100081, China \\ ${ }^{3}$ State Key Laboratory of Atmospheric Boundary Layer Physics and Atmospheric Chemistry (LAPC), the Institute of Atmospheric \\ Physics, CAS, Beijing 100029, China \\ ${ }^{4}$ The Center for Atmospheric Environmental Study, Beijing Normal University, Beijing 100875, China \\ ${ }^{5}$ Center for Atmospheric Chemistry Studies, Graduate School of Oceanography, University of Rhode Island, Narragansett, RI \\ 02882-1197, USA \\ ${ }^{6}$ State key Laboratory of Loess and Quaternary Geology, Institute of Earth Environment, CAS, Xian 710075, China
}

Received 28 January 2008, accepted 11 July 2008

\begin{abstract}
Characteristics of individual particles from a super dust storm (DS) on 20 March 2002, and those of non dust storm aerosols for Beijing (NDS) and Duolun (DL) (a desert area) are determined using a variety of methods. In China, typically the source of aerosols in dust storms is thought to be deserts with aluminosilicates being the main constituent particles; however, this does not reflect a complete analysis with our evidence indicating potential alternate dust sources along the storm's transport path. Individual particle analysis of aerosols collected from a super dust storm on 20 March 2002 in Beijing shows that among all the 14 elements measured, only $\mathrm{S}$ and $\mathrm{Cl}$ have remarkable positive correlation. $82.5 \%$ of all particles measured contained both $\mathrm{S}$ and $\mathrm{Cl}$, and the relative mass percentage of $\mathrm{S}$ and $\mathrm{Cl}$ in these particles is much higher than the average of all particles. $62.0 \%$ of all particles contained $\mathrm{S}, \mathrm{Cl}$, and $\mathrm{Na}$, in which the concentration of $\mathrm{Na}$ is 1.4 times higher than average. PMF (Positive Matrix Factorization) analysis indicates that $\mathrm{NaCl}$ and $\mathrm{Na}_{2} \mathrm{SO}_{4}$ are major components of these particles with $\mathrm{S}$ and $\mathrm{Cl}$ showing significant positive correlation. Moreover, $\mathrm{SO}_{4}{ }^{2-}$ and $\mathrm{Cl}^{-}$also show significant positive correlation in bulk aerosol analysis. XPS (X-ray Photoelectron Spectroscopy) analysis of the surface of aerosols demonstrates that concentrations of $\mathrm{Na}$ and $\mathrm{S}$ on particles from the dust storm are higher than those from non-dust storm particles in Beijing and also for particles from. It is very likely that particles enriched with $\mathrm{S}, \mathrm{Cl}$, and $\mathrm{Na}$ is from the surface soils of dried salt-lakes and saline soils enriched with chloride and sulfate. This evidence demonstrates that besides deserts, surface soils from dry salt-lakes and saline soils of arid and semi-arid areas are also sources of particulates in dust storms over Beijing.
\end{abstract}

Key words: Dust storm, Individual particle analysis, Correlation of $\mathrm{S} / \mathrm{Cl}$, Salt lake and saline soil

Citation: Zhang, X., G. Zhuang, H. Yuan, K. A. Rahn, Z. Wang, and Z. An, 2009: Aerosol particles from dried salt-lakes and saline soils carried on dust storms over Beijing. Terr. Atmos. Ocean. Sci., 20, 619-628, doi: 10.3319/TAO.2008.07.11.03(A)

\section{INTRODUCTION}

Dust storms, which arise in desert and loess areas of northwestern China and sweep over the major cities of Northern China, such as Beijing, each spring, have become increasingly intense over the past few years (Cyranoski 2003).

\footnotetext{
* Corresponding author

E-mail:gszhuang@fudan.edu.cn
}

Dusts driven by strong westerly winds accompanying cold fronts are transported long distances to Korea, Japan, the Pacific Ocean, and even as far as North America (Duce et al. 1983; Gao et al. 1992; Mori et al. 2002 etc.). About half of the dust from deserts in China and Asia is finally deposited in seas near China and the remote Pacific Ocean (Arimoto et al. 1996; Zhang et al. 1997). The loose loess in 
arid and semi-arid areas in northwestern China and Inner Mongolia is the main source of dust in China's storms. Yuan et al. (2006) collected soil samples at various land surfaces in Central Inner Mongolia. These were resuspended using a dry powder atomizer in an enclosure chamber to identify the origin of Asian sands for tracing them as they traveled downwind. Zhang et al. (2003) and Zhuang et al. $(2001,2003)$ studied the physicochemical characteristics of dust storms and their impacts on global climate during long-range transport in China in 2000, 2001, and 2002. Wang et al. (2004) discussed transport pathways and sources of PM10 pollution in Beijing during spring 2001, 2002, and 2003 and found that the pathways and sources of polluting aerosols are associated with Asian dust emissions. Recently Zhuang et al. $(1992,2003)$ further demonstrated the mechanism of coupling and feedback between iron and sulfur in air-sea exchange and concluded that transport in dust storms is an important path in global biogeochemical cycles.

Many scientists have paid a good deal of attention to the characterization of bulk aerosols in dust storms (Zhuang et al. 2001; Sun et al. 2004, etc.), while few have carried out individual particle analysis, which can give much more information on heterogeneous reactions, morphometrics, and transformation during long-range transport. A difficulty with analysis of bulk aerosols is that it does not different particles from different sources. Yet, individual particle analysis can provide useful information on the original source and chemical transformation of chemical species during longrange transport. Gao and Anderson (2001) analyzed single aerosol particles (using automated SEM) collected from Beijing, Qingdao, and Waliguan during April 1999 and revealed that the particulate matter of each region are complex, heterogeneous mixtures of soil dust with anthropogenic particles from various sources. Using image analysis Whittaker et al. (2003) found that particles in dust storm samples of PM10 at Beijing are a mixture of soot, smelter pollutants, loess and gypsum. Shi et al. (2003) also distinguished particles collected over Beijing to be soot, fly ash, and minerals by using image analysis. Zhang et al. (2000, 2003) reported that single particles from both dust storm and non dust storm samples collected from Qingdao, a costal city, were coated by sulfate and nitrate.

Here we report new findings based on individual particle analysis in addition to XPS, IC analysis for aerosol samples collected from a super dust storm over Beijing. The results demonstrate that besides deserts, particulate matter was generated from the surface soils of dry salt-lakes and the saline soils of arid and semi-arid areas.

\section{EXPERIMENTAL SECTION}

\subsection{Sampling of Aerosol Particles}

Samples were collected on 20 March 2002 when a super dust storm (DS) covered Beijing $\left(39.9^{\circ} \mathrm{N}, 116.4^{\circ} \mathrm{E}\right)$ accompanied by strong winds of $\sim 10 \mathrm{~m} \mathrm{~s}^{-1}$. Sampling was conducted at between 15:30 - 19:50, just after the dust peaked. Two TSP samples were also collected on non dust storm days: one from Beijing (designated as "NDS", sampled at $8: 30-10: 30$ on 25 July 2002 , clear weather), and the other from Duolun (designated as "DL", $42.2^{\circ} \mathrm{N}, 116.4^{\circ} \mathrm{E}$, sampled at 12:06 - 17:40 on 19 April 2002, clear weather). DS and NDS were taken on the roof of the Science and Technology Building of Beijing Normal University, twelve stories ( $\sim 40 \mathrm{~m}$ ) above the ground. DL was collected on the roof of a three-story building at Duolun Middle School. Aerosol samples were collected on Nuclepore polycarbonate membrane filters of $0.6-\mu \mathrm{m}$ pore size and $90-\mathrm{mm}$ diameter with a medium-volume sampler (model: TSP/PM $\mathrm{PM}_{10} / \mathrm{PM}_{2.5}$-2; flow rate: $77.59 \mathrm{~L} \mathrm{~min}^{-1}$ ) manufactured by Beijing Geological Instrument-Dickel Co., Ltd. The aerosols samples for ion chromatographic (IC) analysis were collected on a Whatman4l filter membrane (Whatman Co., UK). Sample filters were put in a polyethylene plastic bag immediately after sampling. After weighing (Sartorius 2004MP Electronic balance, $0.01 \mathrm{mg}$ ) under constant temperature and humidity, the samples were refrigerated for later analysis. All procedures were strictly monitored to avoid any possible contamination.

\subsection{Individual Particles Analysis}

Individual particles were analyzed with a HITACHI X650 Scanning Electron Microscope (SEM) coupled with an energy-dispersive X-ray microanalyzer (EDX) following EDX 9100's procedures. The operating conditions were set to $20-\mathrm{kV}$ (accelerating voltage) and 40-pA (beam current) with spectral acquisition time of $60-100 \mathrm{~s}$. A $1-\mathrm{cm}^{2}$ piece of the filter was mounted on a stub and coated with a thin graphite film by heating and sputtering. We randomly selected several areas on the filter with relatively low particle density and analyzed all the particles in these areas for 14 elements. Carbon and oxygen were not considered because they were too abundant in the polycarbonate filters. The intensities of the characteristic X-ray lines of each element were converted into their corresponding atomic fractions by the standard ZAF correction method - The method calculates the effects of atomic number $(\mathrm{Z})$, absorption (A), and characteristic (and sometimes continuum) fluorescence (F), separately. The abundance of each oxide in the particles was determined with the standardized oxide method for EDX, which assumes that each element (except $\mathrm{Cl}$ ) exists as an oxide and sums the 14 abundances of the elements to $100 \%$. Geometry effects that arise from the finite size of micro particles introduce a systematic error, but this error has little effect on the characterization of particle types (Gao and Anderson 2001). In all, we measured 565 single particles from DS, 419 from NDS, and 498 from DL. Details of the 
method used are given in Yuan et al. 2004.

\subsection{Ion Chromatographic (IC) Analysis}

$\mathrm{SO}_{4}{ }^{2-}$ and $\mathrm{Cl}^{-}$were analyzed for the samples collected during the dust storm with a Dionex 600 IC system that consists of an anion separation column (Dionex Ionpac AS11), a guard column (Dionex Ionpac AG11), a self-regenerating suppressed conductivity detector (Dionex Ionpac ED50), and a gradient pump (Dionex Ionpac GP50). Peaknet 6 software was used for chromatographic data processing. The filters were extracted in an ultrasonic cleaner and filtered through $0.45-\mu \mathrm{m}$ microporous membranes $(\Phi 25 \mathrm{~mm})$, and the extracts were then injected into the IC with polypropylene syringes (Yuan et al. 2003).

\subsection{X-Ray Photoelectron Spectroscopy (XPS) Analysis}

The surface composition and structure of the aerosols was measured using XPS (PHI 5000C ESCA System, 14 kV, $250 \mathrm{~W}, 93.9 \mathrm{eV}$, exciton, $\mathrm{AlK}$ a, scanning range for acquiring spectroscopy, 0 - $1200 \mathrm{eV}$, Perkin Elmer Company, USA). The minute spectroscopies of 10 elements $\left(\mathrm{C}_{1 \mathrm{~s}}, \mathrm{O}_{1 \mathrm{~s}}, \mathrm{Na}_{1 \mathrm{~s}}\right.$, $\mathrm{Mg}_{2 \mathrm{p}}, \mathrm{Al}_{2 \mathrm{p}}, \mathrm{Si}_{2 \mathrm{p}}, \mathrm{S}_{2 \mathrm{p}}, \mathrm{Ca}_{2 \mathrm{p}}, \mathrm{Mn}_{2 \mathrm{p}}$, and $\mathrm{Fe}_{2 \mathrm{p}}$ ) were acquired. A special software (PHI-MATLAB) was used for data analysis. The binding energy of polluted $\mathrm{C} 1 \mathrm{~s}(284.8 \mathrm{eV})$ was used in calibration to confirm the binding energy of all other elements.

The relative concentrations of atoms are calculated by the following formula (Boudevilie et al. 1979):

$$
\frac{n_{i}}{n_{j}}=\frac{I_{i}}{I_{j}} \cdot \frac{\sigma_{i}}{\sigma_{j}} \cdot\left(\frac{E_{k j}}{E_{k i}}\right)^{1 / 2}
$$

Where $n$ is the atom number over the aerosol surface, $I$ is the intensity of XPS, $\sigma$ is the area of the element in some energy level, and $E_{k}$ is the kinetic energy of the photoelectron. Details of the method are given in Zhang et al. (2005).

\subsection{PMF Factor Analysis}

Positive Matrix Factorization (PMF) was developed by P. Paatero of the Department of Physics, University of Helsinki, Finland, and marketed jointly by YP-Teekniika K Y Company and the university's Department of Physics. It was first applied to environmental data by Juntto and Paatero (1994). Many works have shown it to be an effective and novel method for source apportionment of aerosol particles (Huang et al. 1999). PMF is a powerful tool that can work without original source information, provide all the nonnegative loadings of the elements in matrix, and optimize results by adjusting the standard deviation of each data point. Suppose $\mathrm{X}$ is a matrix with $\mathrm{n} \times \mathrm{m}$, where $\mathrm{n}$ is the number of samples and $\mathrm{m}$ is the number of chemical components, including all ions, elements and organisms. Then X can be divided into $\mathrm{GF}+\mathrm{E}$, where $\mathrm{G}$ is the matrix of $\mathrm{n} \times \mathrm{p}$, and $\mathrm{F}$ is the matrix of $p \times m$ with $p$ being the number of main pollution sources. E is a matrix defined as follows:

$e_{i j}=x_{i j}-\sum_{h=1}^{p} g_{i h} f_{h j} \quad Q=\sum_{i=1}^{m} \sum_{j=1}^{n}\left(e_{i j} / h_{i j} s_{i j}\right)^{2}$

where $S_{i j}$ is the standard deviation. The restriction condition is that the elements in $\mathrm{G}$ and $\mathrm{F}$ are all nonnegative. $\mathrm{E}$ can acquire optimized results and confirmed $\mathrm{G}$ and $\mathrm{F}$ by comparing $\mathrm{Q}$ values. Usually $\mathrm{F}$ is considered a load matrix and $\mathrm{G}$ the figure matrix of the sources.

\section{RESULTS AND DISCUSSION}

\subsection{General Descriptions}

The mass fraction and the number fraction [the ratio of the number of particles, in which the element of interest was detected, to the total number of particles measured, also called number frequency (see below)] of each element in the samples of DS, DL, and NDS were reported in Yuan et al. 2006. The results show that: (1) the major elements, including $\mathrm{Al}, \mathrm{Si}, \mathrm{P}, \mathrm{S}$, and $\mathrm{Ca}$ were abundant in single particles of DS, DL, and NDS, whose number fractions were close to $100 \%$; (2) Both Si and $\mathrm{Al}$ are dominant in the particles of DS and $\mathrm{DL}$, and the sum of $\mathrm{Si}$ and $\mathrm{Al}$ accounted for $\sim 65 \%$ of the total; whereas, greater numbers of $\mathrm{S}, \mathrm{P}$, and $\mathrm{Cl}$ were found in NDS, the sum of these three elements contributed $35 \%$ of the total; (3) Na and Mg in NDS were highest among the three samples, indicating that $\mathrm{Na}$ and $\mathrm{Mg}$ in NDS were partly from pollution; whereas, $\mathrm{K}$ was greater in DS and DL than in NDS, indicating that more $\mathrm{K}$ was from dust, as with $\mathrm{Si}$ and $\mathrm{Al}$; (4) $\mathrm{Cu}$ in DL had an extremely high number frequency (96.8\%), revealing there must be a special source of $\mathrm{Cu}$ nearby. Fan et al. (1996) reported the number frequencies of $\mathrm{Mg}, \mathrm{K}, \mathrm{Ca}$, and $\mathrm{Fe}$ in dust storm particles collected in April 1991 in Beijing were all above 62\%, results which were similar to this study. However, in this study we found very high number frequencies of $\mathrm{S}(99.5 \%)$ and $\mathrm{Cl}(82.5 \%)$ in DS; these values were much higher than that of S $(14 \%)$ and $\mathrm{Cl}(0 \%)$ in the dust storm of 1991.

\subsection{Composition and Size Distribution of Individual Particles}

The highest recorded TSP hourly concentration was $10.90 \mathrm{mg} \mathrm{m}^{-3}$ for the DS period of 20 March 2002. This was 36 times higher than TSP concentration recorded during the non-DS. The $12 \mathrm{hr}$-averaged $\mathrm{PM}_{2.5}$ concentrations also reached $1.39 \mathrm{mg} \mathrm{m}^{-3}$ (Sun et al. 2004). The size distribution 
and the morphology of the particles (morphology varies with particle size) were measured with SEM images of single particles. Particle sizes ranged from $\sim 0.3$ to $\sim 20 \mu \mathrm{m}$. The median sizes were $\sim 1.3 \mu \mathrm{m}$ for DS particles, $\sim 0.8 \mu \mathrm{m}$ for NDS particles, and $1.2 \mu \mathrm{m}$ for DL particles. For DS particles, $>80 \%$ were $<2.5 \mu \mathrm{m}$, which is respirable.

The average relative mass percentages of $\mathrm{SO}_{3}$ and $\mathrm{Cl}$ in DS particles were $6.42 \%$ and $0.57 \%$ with the highest proportions of $97.39 \%$ and $11.43 \%$, respectively. The percentage of $(\mathrm{S}+\mathrm{Cl})$-containing particles constituting the total particles measured was $82.5 \%$; the average relative mass percents of $\mathrm{SO}_{3}$ and $\mathrm{Cl}$ were $6.70 \%$ and $0.58 \%$, respectively, which were higher than the overall $(\mathrm{n}=565)$ averages $(2.6 \%$ and $0.42 \%$, respectively). The $(\mathrm{S}+\mathrm{Cl}+\mathrm{Na})$-containing particles represented $62.0 \%$ of the total particles measured; the relative mass percent of $\mathrm{Na}$ was $6.10 \%$, and 1.4 times that of the overall mean (4.36\%). These results showed that the three elements $\mathrm{Na}, \mathrm{S}$, and $\mathrm{Cl}$ were enriched in some DS particles. The proportion of Na-containing particles with relative mass percent of $>15 \%$ in the DS sample was $1.24 \%$ of the total, which is 5 times higher than that $(0.24 \%)$ in the NDS sample from Beijing. The relative mass percent of $\mathrm{Na}$ in the DL particles was $1.54 \%$, which is lower than that (4.36\%) in the DS sample from Beijing. The size of those S-enriched particles with a relative mass percent of $15 \% \mathrm{~S}$ was $<1.0 \mu \mathrm{m}$, indicating that these S-enriched fine particles were mostly from secondary pollutants. In contrast, $(\mathrm{S}+\mathrm{Cl})$-containing particle size was $>1.0 \mu \mathrm{m}$. This indicates that those particles were mostly primary and their sources were likely the same though not from deserts, in which Si dominates the coarse particles. The PMF analysis showed that the major components in the $(\mathrm{Na}+\mathrm{S}+\mathrm{Cl})$-rich particles were $\mathrm{Na}_{2} \mathrm{SO}_{4}$ and $\mathrm{NaCl}$, and the number of these particles was $9 \%$ of total particles. We have identified $(\mathrm{Na}+\mathrm{S}+\mathrm{Cl})$-containing particles from the spectrum of the EDX analysis and the SEM images, as shown in Fig. 1a. Additionally, the common particles in the DS samples are aluminosilicate particles enriched in $\mathrm{Si}, \mathrm{Al}$, and $\mathrm{Ca}$, as indicated in Fig. 1b. These results demonstrate that particles that were enriched by a combination of $\mathrm{S}, \mathrm{Cl}$, and $\mathrm{Na}$ during DS were likely not from deserts.

\subsection{Correlation Analysis of the Elements in Individual Particles}

Table 1 lists the result of correlation analysis by STATISTICA ${ }^{\circledR}$. Surprisingly, among the 14 elements measured

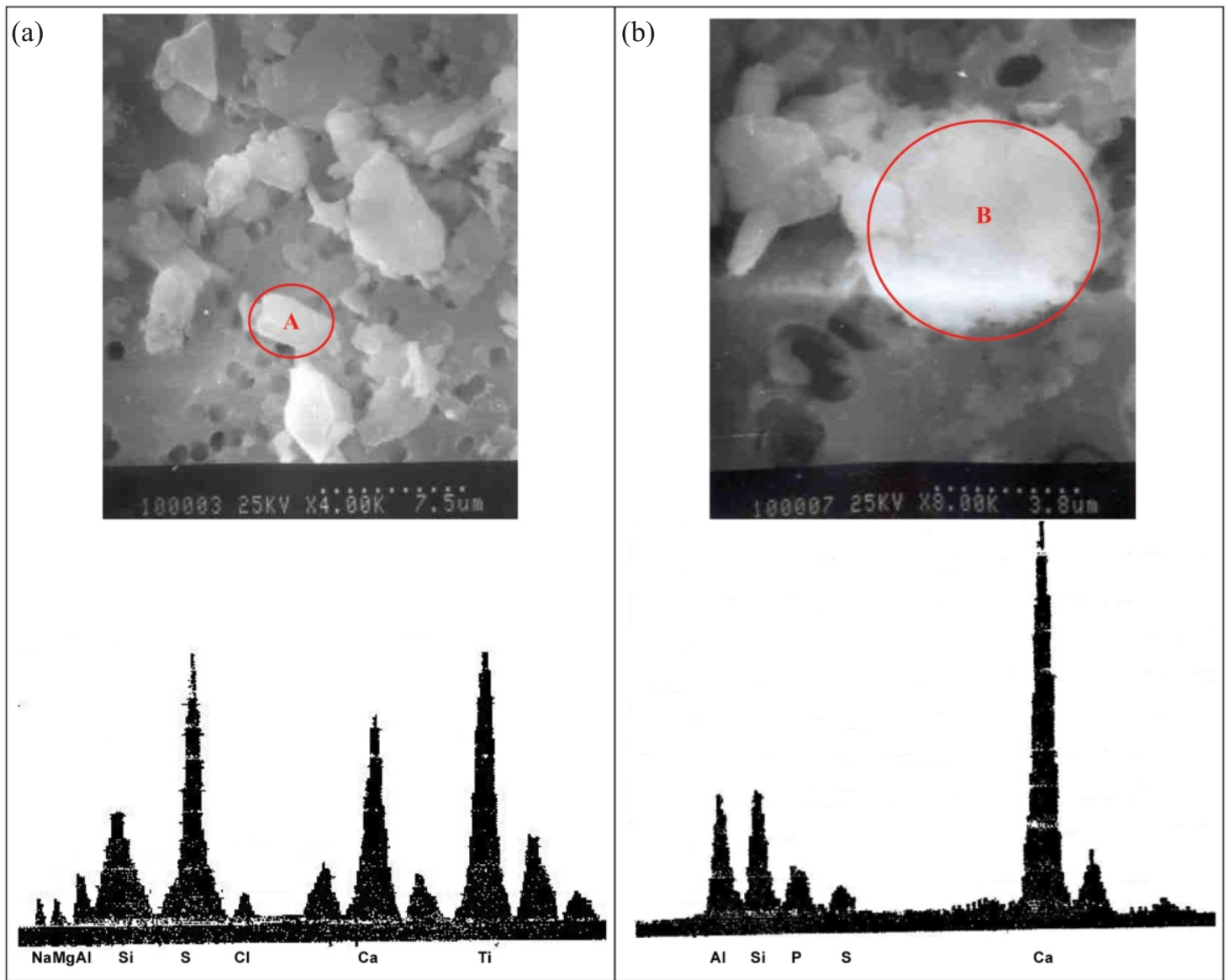

Fig. 1. Spectrum of a certain individual particle of duststorm aerosol by EDX: (a) S- and Cl-rich particle; (b) common dust particle. 
Table 1. Correlation of relative mass percentage of elements in particles of the dust storm.

\begin{tabular}{|c|c|c|c|c|c|c|c|c|c|c|}
\hline \multicolumn{11}{|c|}{ Dust storm in Beijing } \\
\hline Wt $\%$ & $\mathrm{Na}_{2} \mathrm{O}$ & MgO & $\mathbf{A l}_{2} \mathbf{O}_{3}$ & $\mathrm{SiO}_{2}$ & $\mathbf{P}_{2} \mathbf{O}_{5}$ & $\mathrm{SO}_{3}$ & Cl & $\mathbf{K}_{2} \mathbf{O}$ & $\mathrm{CaO}$ & $\mathrm{Fe}_{2} \mathrm{O}_{3}$ \\
\hline $\mathrm{Na}_{2} \mathrm{O}$ & 1.00 & & & & & & & & & \\
\hline MgO & 0.27 & 1.00 & & & & & & & & \\
\hline $\mathrm{Al}_{2} \mathbf{O}_{3}$ & 0.09 & 0.30 & 1.00 & & & & & & & \\
\hline $\mathrm{SiO}_{2}$ & -0.26 & -0.44 & -0.16 & 1.00 & & & & & & \\
\hline $\mathbf{P}_{2} \mathbf{O}_{5}$ & -0.37 & -0.30 & -0.28 & -0.13 & 1.00 & & & & & \\
\hline $\mathrm{SO}_{3}$ & -0.20 & -0.34 & -0.45 & -0.33 & 0.49 & 1.00 & & & & \\
\hline $\mathbf{C l}$ & -0.20 & -0.24 & -0.33 & -0.28 & 0.41 & $\underline{0.75}$ & 1.00 & & & \\
\hline $\mathbf{K}_{2} \mathbf{O}$ & -0.17 & -0.10 & 0.29 & 0.07 & -0.30 & -0.13 & -0.05 & 1.00 & & \\
\hline $\mathrm{CaO}$ & 0.10 & 0.19 & -0.22 & -0.44 & -0.09 & -0.08 & -0.08 & -0.16 & 1.00 & \\
\hline $\mathrm{Fe}_{2} \mathrm{O}_{3}$ & 0.10 & 0.32 & 0.12 & -0.22 & -0.38 & -0.29 & -0.23 & 0.05 & -0.08 & 1.00 \\
\hline
\end{tabular}

as individual particles in DS, only one pair of elements, $\mathrm{S}$ with $\mathrm{Cl}$, show good correlation (the correlation coefficient being $0.75, \alpha=0.05, p<<0.01)$. Correlation coefficients are only 0.53 in NDS samples and 0.07 in DL samples, respectively. It is clear that aerosol particles in DS are different to those particles of NDS and both DS and NDS particles are different again to the non-dust particles of DL, although the desert of Duolun, Inner Mongolia was considered to be a major source of aerosols for dust storms over Beijing. It must be noted that individual particle analysis is different to bulk aerosol analysis. The concentrations of crustal elements, such as $\mathrm{Si}, \mathrm{Al}$, and $\mathrm{Fe}$, normally show positive correlation in bulk aerosol samples collected at different times and sites; whereas, the results from individual particle analysis do not show such a relationship (Yuan et al. 2006). Individual particle analysis gives information regarding an individual particle from a large number of particles in an aerosol sample; this does not present information regarding bulk analysis. Figure 2 shows a marked positive correlation between $\mathrm{Cl}$ and $\mathrm{S}$ in individual dust particles with an average ratio $\mathrm{Cl} / \mathrm{SO}_{3}$ of 0.09 , which is close to the world average ratio for soil [0.06, from Bowen (1966)]. However, the ratio of $\mathrm{Cl} / \mathrm{Al}_{2} \mathrm{O}_{3}$ was ten times that of world soil. This sole correlation of $\mathrm{Cl}$ with $\mathrm{S}$ and the high ratio of $\mathrm{Cl} / \mathrm{Al}_{2} \mathrm{O}_{3}$ imply that $\mathrm{Cl}$ and $\mathrm{S}$ might come from an identical source where the soil has been enriched with both $\mathrm{S}$ and $\mathrm{Cl}$. It is well known that dry salty lakes and saline soils in Inner Mongolia, which contain both $\mathrm{Na}_{2} \mathrm{SO}_{4}$ and $\mathrm{NaCl}$ (Yang 1996), lay on the path of dust storms, thus, dust storms would very likely pick up these particles here. The high correlation between $\mathrm{Cl}$ and $\mathrm{S}$ in dust storm particles suggests that these saline soils could be a source of particulates for dust storms (Yuan et al. 2006). This analysis can also explain why a number of dust particles containing $\mathrm{Na}, \mathrm{S}$, and $\mathrm{Cl}$ of crustal origins were found over Qingdao before passing across the ocean (Zhang et al. 2003).

\subsection{Ternary Plots Analysis}

Ternary plots (Yuan et al. 2004) of three major components [clay and quartz $\left(\mathrm{Al}_{2} \mathrm{O}_{3}, \mathrm{SiO}_{2}\right.$, etc. $)$, calcite $\left(\mathrm{CaCO}_{3}\right.$, $\mathrm{CaO}$ ), and salts (sulfate, phosphate, chloride)] of single particles revealed that $\mathrm{Na}_{2} \mathrm{SO}_{4}$ and $\mathrm{NaCl}$ might be externally/internally mixed in the DS particles. Yuan et al. (2006) proved that the $\mathrm{CaCO}_{3}, \mathrm{CaO}, \mathrm{CaSO}_{4}$, and salts, i.e., sulfate and phosphate plus chloride, such as $\left(\mathrm{NH}_{4}, \mathrm{Na}\right)_{\mathrm{x}}\left(\mathrm{SO}_{4}, \mathrm{Cl}, \mathrm{PO}_{4}\right)_{\mathrm{y}}$, mixed with clay and quartz in those particles.

\subsection{Compositions and Correlations of the Soluble Ions}

Figure 3 shows the concentrations of the $\mathrm{SO}_{4}{ }^{2-}$ and $\mathrm{Cl}^{-}$in

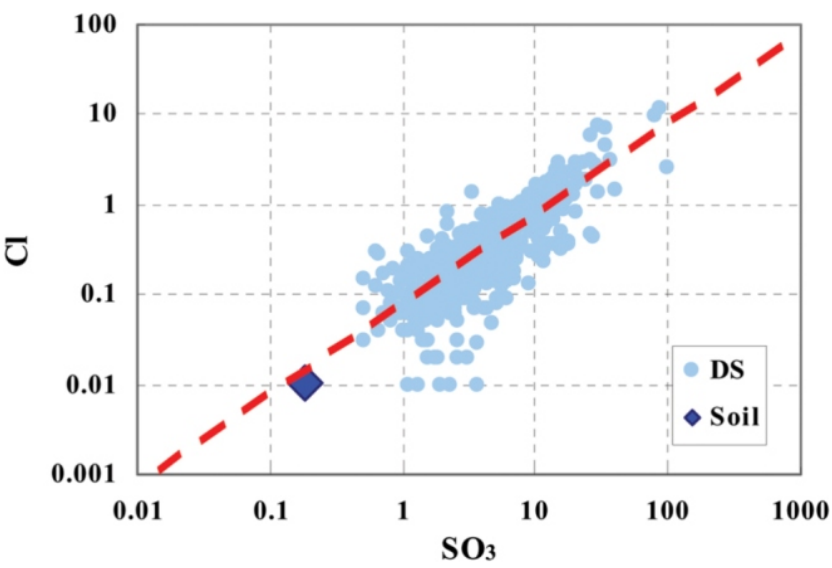

Fig. 2. Relationship between $\mathrm{SO}_{3}$ and $\mathrm{Cl}$ in individual particles of the duststorm aerosol. 

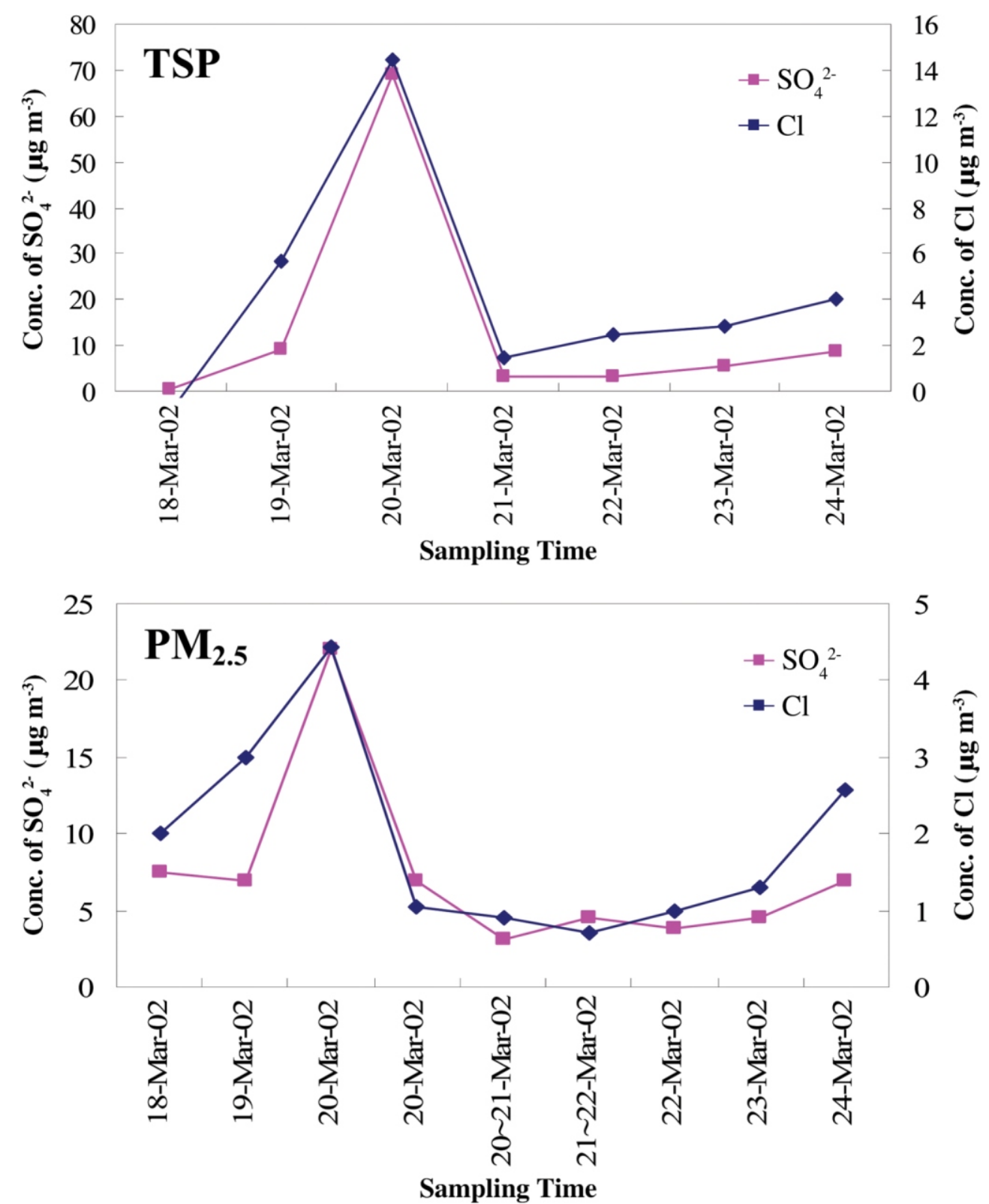

Fig. 3. Variations of $\mathrm{SO}_{4}{ }^{2-}$ and $\mathrm{Cl}^{-}$in TSP and $\mathrm{PM}_{2.5}$ samples.

the TSP and $\mathrm{PM}_{2.5}$ samples collected during DS. The concentrations of the $\mathrm{SO}_{4}{ }^{2-}$ and $\mathrm{Cl}^{-}$tracked each other. The average concentrations of $\mathrm{SO}_{4}{ }^{2-}$ and $\mathrm{Cl}^{-}$during DS are 1.95 and $0.48 \mathrm{mg} \mathrm{g}^{-1}$, respectively. These results are 27 and 8 times those of DL $\left(\mathrm{SO}_{4}{ }^{2-} 0.07 \mathrm{mg} \mathrm{g}^{-1}, \mathrm{Cl}^{-} 0.06 \mathrm{mg} \mathrm{g}^{-1}\right)$. It has been reported that concentrations of $\mathrm{SO}_{4}{ }^{2-}$ and $\mathrm{Cl}^{-}$in typical salty soils in North China are 1.4 and $1.5 \mathrm{mg} \mathrm{g}^{-1}$ (Jiang and Zhang 2001). Comparing all these results, it is clear that there are more $\mathrm{S}$ and $\mathrm{Cl}$ in the individual particles of DS, implying that there must be other sources than deserts generating these particles, such as saline soil enriched with $\mathrm{S}$ and $\mathrm{Cl}$ components.

Figure 4 illustrates concentrations and correlation of
$\mathrm{SO}_{4}{ }^{2-}$ and $\mathrm{Cl}^{-}$of six aerosol samples collected sequentially during DS. The sampling times were: 10:20 - 12:20, 12:22 14:22, 14:25 - 16:25, 16:25 - 18:25, 18:25 - 20:25, and 20:25 $-22: 25$. The figure shows a very positive correlation $\left(\mathrm{R}^{2}=\right.$ 0.9908 ) between $\mathrm{SO}_{4}{ }^{2-}$ and $\mathrm{Cl}^{-}$in these samples. Beijing is an inland city, and wind direction on the day of the storm was from the northwest or north at more than $10 \mathrm{~m} \mathrm{~s}^{-1}$. $\mathrm{Cl}^{-}$could not have come from the sea, which is located to east or southeast. Given the positive relationship between results for individual particle analyses and $\mathrm{IC}$ analysis for $\mathrm{S}$ and $\mathrm{Cl}$ and the prevailing winds during DS, it is likely that $\mathrm{S}$ and $\mathrm{CL}$ share a common source somewhere on the path of the dust storm to the northwest or north of Beijing. 


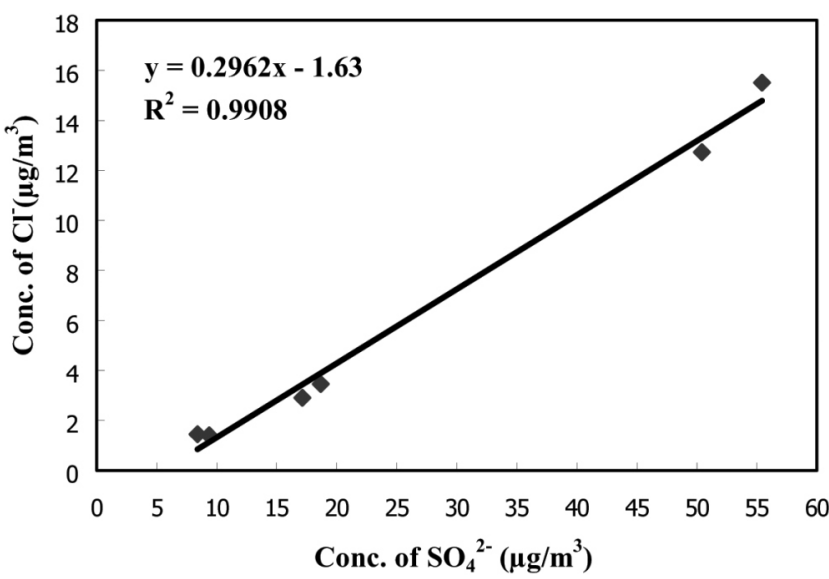

Fig. 4. Liner regression of $\mathrm{SO}_{4}{ }^{2-}$ and $\mathrm{Cl}^{-}$in dust storm day, 20 March 2002.

\subsection{PMF Factor Analysis of the Elements in Individual Particles}

The results of the 565 individual particles collected during DS, 419 particles of NDS, and 498 particles of DL have been analyzed by PMF2, which has been successful in getting source appointments of aerosol particles in Hong Kong, Thailand, and Spain, etc. (Huang et al. 1999; Lee et al. 1999; Predes et al. 1999; Jiang and Zhang 2001). The result of $\mathrm{PMF}$ analysis show that $\mathrm{S}$ and $\mathrm{Na}$ are of the same factors $\left(55 \% \mathrm{SO}_{3}, 41 \% \mathrm{Na}_{2} \mathrm{O}\right.$, and $\left.36 \% \mathrm{P}_{2} \mathrm{O}_{5}\right)$, indicating that $\mathrm{Na}_{2} \mathrm{SO}_{4}$ was a major component of sulfates in the dust aerosols. The results from graphic technique analysis based on the SEM data also demonstrate that $\mathrm{Na}_{2} \mathrm{SO}_{4}$ is the main contributor to this factor in dust aerosol particles (Yuan et al. 2004). According to graphic analysis of individual particles, $\left(\mathrm{NH}_{4}\right) \mathrm{XS}_{4}$ existed in dust aerosols, though in small numbers, thus giving $\mathrm{Na}_{2} \mathrm{SO}_{4}$ as the major sulfate. $\mathrm{Cl}, \mathrm{Na}$, and $\mathrm{Mg}$ are of the same factor for the samples of DS, in which the ratio of $\mathrm{Cl} / \mathrm{Na}$ is 5 . This is quite different to its ratio in seawater (1.8), which is normally based on the existence of both $\mathrm{NaCl}$ and $\mathrm{MgCl}_{2}$. As previously discussed northwesterlies or northlies prevailed during DS, making it impossible for sea salts to be a factor in the particulate matter of DS and suggesting that particles enriched with $\mathrm{Na}$ and $\mathrm{Cl}$ were sourced from saltpans and saline soils in northwest and northern China. This is further evidenced by the main components of soils from saltpans and saline soils being rock salt $(\mathrm{NaCl})$ and Glauber's salt $\left(\mathrm{Na}_{2} \mathrm{SO}_{4}\right)(\mathrm{Xu} 1993)$.

\subsection{Surface Analysis by XPS}

The XPS (X-ray photoelectron spectroscopy) analysis is an excellent method for studying particle surface structure and composition. Table 2 lists XPS results of samples collected during DS. The relative mass concentration percentage of $\mathrm{Na}$ on the surface was $0.30 \%$ in particles from DS,
$0.27 \%$ for NDS and $0.18 \%$ for DL, indicating greater $\mathrm{Na}$ enrichment of DS particles. This result again confirms that there must have been an alternate source for $\mathrm{Na}$ on the storm's path as it traveled toward Beijing. XPS results also reveal the relative mass concentration percentage of $\mathrm{S}$ on the surface to be $0.80 \%$ for DS particles, a result higher than that for both NDS and DL samples $(0.39 \%)$. Similarly, these results along with those of SEM and PMF analyses indicate another source besides the desert as being responsible for $\mathrm{S}$, $\mathrm{Na}$, and $\mathrm{CL}$ levels in DS particles.

\subsection{Source of Those Particles Enriched with S, Cl, and $\mathrm{Na}$}

Okada and Kai (2004) analyzed soil samples collected at Qira in the Taklamakan Desert by EDX and found that 'Cl-rich' and 'Na-rich' particles were detected in approximately $10 \%$ of total particles. The backward trajectory from $500 \mathrm{~m}$ above Qira at the time of sampling showed that the air parcel did not arrive from over oceanic areas within the previous five days. The presence of atmospheric halite particles in the Taklamakan Desert was reported by Molnár et al. (1993) and Yabuki et al. (1998, 2002). Hence, 'Cl-rich' and 'Na-rich' particles were suggested to be mainly composed of halite. The 'Na-rich' particles contained $\mathrm{S}$ as the second most abundant element, excluding $\mathrm{Cl}$. A 'S-dominant' particle was isolated from the two samples. This particle was evaporated upon irradiation with an electron beam, leading the researchers to conclude that it was composed of sulfate not originating from a mineral source; however, they did not explore further the possible sources of those particles containing $\mathrm{S}, \mathrm{Cl}$, and $\mathrm{Na}$.

For DS two possible paths existed for the storm's approach: north and northwest (Ren et al. 2003). Figure 5 shows that all kinds of chloride-sulphate saline soils exist in the transport pathway of DS. Strong wind could have carried these particles enriched with $\mathrm{S}$ and $\mathrm{Cl}$ and transported them to Beijing. The saline soils cover an area of about $763.01 \times$ $10^{4} \mathrm{hm}^{2}$ in Inner Mongolia, these account for $21 \%$ of China's total $\left(3630.53 \times 10^{4} \mathrm{hm}^{2}\right)$ (Fan and Ma 2001). There are also a great number of salt lakes in Inner Mongolia (Li et al. 1990; Xu 1993). The A'LaShan salt lake area to the north and northwest of Beijing is one of four major salt lake areas in Inner Mongolia, and it lies on the dust transport path to Beijing. Because of continual drought in recent years, there are many saltpans in these salt-lake areas. The main components of the saltpans are rock salt $(\mathrm{NaCl})$ and Glauber's salt $\left(\mathrm{Na}_{2} \mathrm{SO}_{4} \cdot 10 \mathrm{H}_{2} \mathrm{O}\right)$ providing an abundant source of $\mathrm{S}$ and $\mathrm{Cl}$ enriched particles. An earlier study (Wang et al. 1987) of aerosol composition in the drylands of northern China reported the composition of aerosols collected at a site (see Fig. 5) located on Tianchi Mountain, east of Urumqi, to be strongly enriched with both $\mathrm{S}$ and $\mathrm{Cl}$. They attributed this enrichment to uppermost soil layers being enriched with $\mathrm{S}$ 
Table 2. Surface analysis of dust aerosol by XPS.

\begin{tabular}{clcc}
\hline Sampling time & Sampling function area & S\% & Na\% \\
\hline 2002.3.20, 15:00 - 18:00 & Beijing dust storm & 0.802 & 0.302 \\
2002.4.19, 12:00 - 17:00 & Inner Mongolia non-dust & 0.397 & 0.187 \\
2002.4.26, 08:00 - 12:00 & Beijing non-dust & 0.983 & 0.271 \\
\hline
\end{tabular}

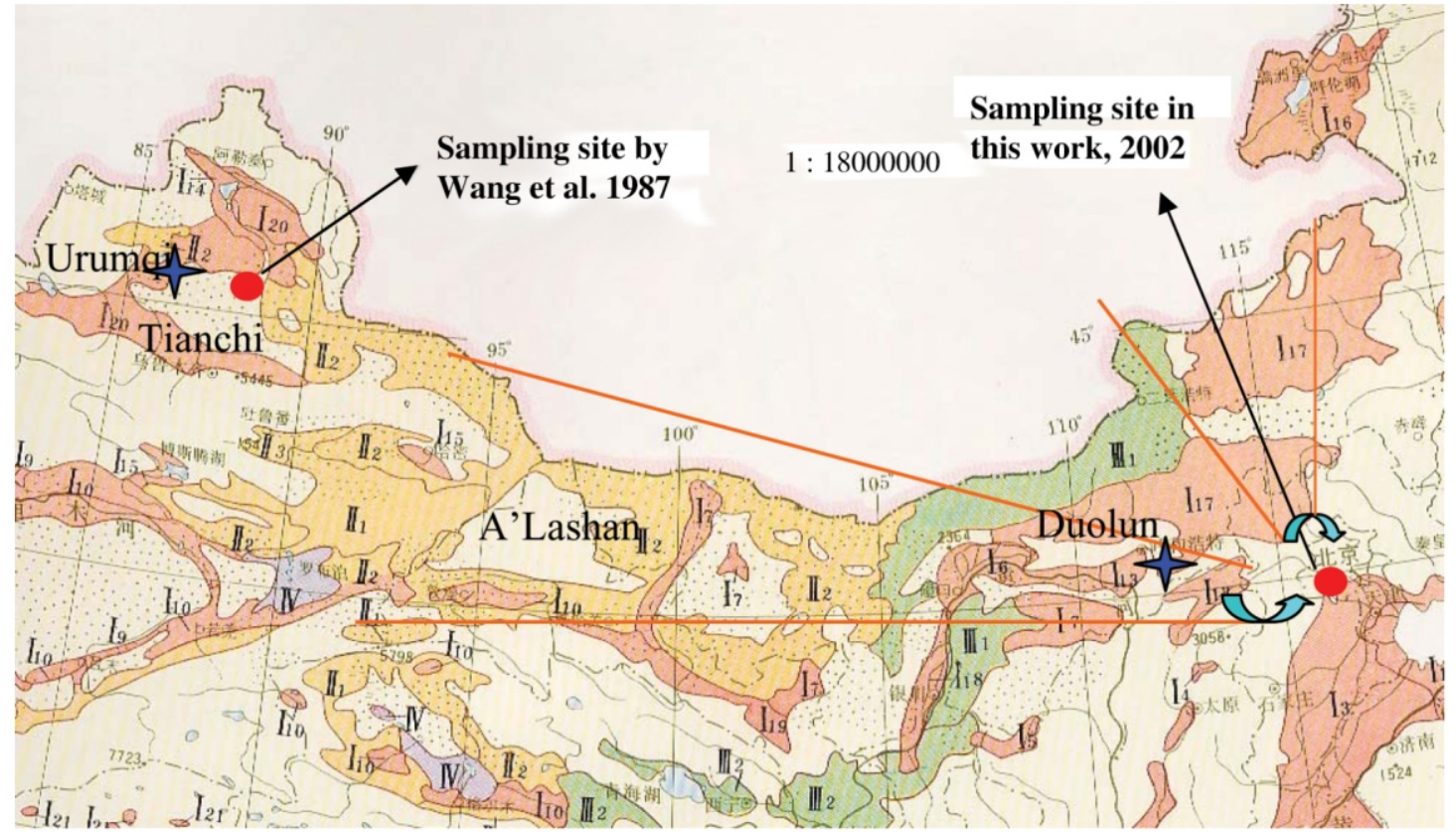

Fig. 5. Distribution of saline soils over Inner Mongolia, China.

Note: 1. two areas with red line mean that two path (North-west path and North path) for dust to Beijing.

2. $\mathrm{I}_{I}, I_{2}$, and $\mathrm{II}_{I}$ mean different types saline soil in China.

and $\mathrm{Cl}$ in this area. It's worth noting that there are many saline soils around this sampling site, $45^{\circ} 53^{\prime} \mathrm{N}, 88^{\circ} 07^{\prime} \mathrm{E}$, such as $\mathrm{I}_{2}, \mathrm{I}_{14}$, and $\mathrm{I}_{20}$ in Fig. 5. These soils are typically enriched with sulfate and chloride. Thus, for this early study, strong wind could have raised surface saline soils during their sampling period giving such results. Thus, our study along and this earlier study both show that besides deserts, surface soils of dry salt-lakes and saline soils in arid and semi-arid areas can provide particulate matter for dust storms.

\section{CONCLUSIONS}

(1) Individual particle analysis of aerosols collected from a super dust storm on 20 March 2002 in Beijing showed that among all the 14 elements measured, only $\mathrm{S}$ and $\mathrm{Cl}$ had remarkable positive correlation.

(2) PMF analysis indicated that $\mathrm{NaCl}$ and $\mathrm{Na}_{2} \mathrm{SO}_{4}$ were major components of these particles, in which $\mathrm{S}$ and $\mathrm{Cl}$ showed significant positive correlation.

(3) The evidence that $\mathrm{S}$ and $\mathrm{Cl}$ in this dust storm were highly related indicates that dried salt-lake and saline soils over northern and northwest China might have contribute to the dust storm's origins.

Acknowledgements This work was supported by the Beijing Urban Meteorology Research Fund (No. UMRF $200704)$, the key projects from the $11^{\text {th }}$ five-year plan of national scientific and technological (2008BAC34B042 ), the fund from State Key Laboratory of Atmospheric Boundary Layer Physics and Atmospheric Chemistry (LAPC-KF-2008-11), National Basic Research Program of China (Nos. 2005CB422202 and 2006CB403702), National Natural Science Funds of China (Grant Nos. 30230310, 20077004, and 20477004), and Beijing Natural Science Funds (Grant Nos. 8991002 and 8041003).

\section{REFERENCES}

Arimoto, R., R. A. Duce, D. L. Savoie, J. M. Prospero, R. Talbot, J. D. Cullen, U. Tomza, N. F. Lewis, and B. J. Ray, 
1996: Relationships among aerosol constituents from Asia and the North Pacific during PEM-West A. J. Geophys. Res., 101, 2011-2023, doi: 10.1029/95JD01071. [Link]

Boudeville, Y., F. Figueras, M. Forissier, J. L. Portefaix, and J. C. Vedrine, 1979: Correlations between X-Ray photoelectron spectroscopy data and catalytic properties in selective oxidation on Sb-Sn-O catalysts. J. Catal., 58, 52-60, doi: 10.1016/0021-9517(79)90243-4. [Link]

Bowen, H. J. M., 1966: Trace Elements in Biochemistry, Academic Press, New York, 166 pp.

Cyranoski, D., 2003: China plans clean sweep on dust storms. Nature, 421, 101, doi: 10.1038/421101a. [Link]

Duce, R. A., R. Arimoto, B. J. Ray, C. K. Unni, and P. J. Harder, 1983: Atmospheric trace elements at Enewetak Atoll: 1, Concentrations, sources, and temporal variability. J. Geophys. Res., 88, 5321-5342, doi: 10.1029/JC088iC09p 05321. [Link]

Fan, X. B., K. Okada, N. Niimura, K. Kai, K. Arao, G. Shi, Y. Qin, and Y. Mitsuta, 1996: Mineral particles collected in China and Japan during the same Asian dust-storm event. Atmos. Environ., 30, 347-351, doi: 10.1016/1352-2310 (95)00271-Y. [Link]

Fan, Z. and Y. Ma, 2001: The saline soil in north areas of China and it improve use. Res. Dry Area, 18, 1-6. (in Chinese)

Gao, Y. and J. R. Anderson, 2001: Characteristics of Chinese aerosols determined by individual-particle analysis. $J$. Geophys. Res., 106, 18037-18045, doi: 10.1029/2000JD 900725. [Link]

Gao, Y., R. Arimoto, M. Y. Zhou, J. T. Merrill, and R. A. Duce, 1992: Relationships between the dust concentrations over eastern Asia and the remote North Pacific. J. Geophys. Res., 97, 9867-9872. [Link]

Huang, S., K. A. Rahn, and R. Arimoto, 1999: Testing and optimizing two factor-analysis techniques on aerosol at Narragansett, Rhode Island. Atmos. Environ., 33, 21692185, doi: 10.1016/S1352-2310(98)00324-0. [Link]

Jiang, Y. and Y. Zhang, 2001: The zoology distribution and characteristics of the saline soil in Shengyang area. Soil Bull., 32, 124-127. (in Chinese)

Juntto, S. and P. Paatero, 1994: Analysis of daily precipitation data by positive matrix factorization. Environmetrics, 5, 127-144, doi: 10.1002/env.3170050204. [Link]

Lee, E., C. K. Chan, and P. Paatero, 1999: Application of positive matrix factorization in particle pollutants in Hong Kong. Atmos. Environ., 33, 3201-3212, doi: 10.1016/ S1352-2310(99)00113-2. [Link]

Li, R., L. Zheng, and G. Zhu, 1990: The Lake and Environment Change of Inner Mongolia Tableland, Beijing Normal University publishing company, $53 \mathrm{pp}$. (in Chinese)

Molnár Á., L. Makra, Y. Chen, and I. Borbély-Kiss, 1993: Some data on the elemental composition of atmospheric aerosol particles in Xinjiang, NW China. Idõjárás, 97, 173-177.

Mori, I., M. Nishikawa, H. Quan, and M. Morita, 2002: Estimation of the concentration and chemical composition of kosa aerosols at their origin. Atmos. Environ., 36, 4569-4575, doi: 10.1016/S1352-2310(02)00489-2. [Link]

Okada, K. and K. Kai, 2004: Atmospheric mineral particles collected at Qira in the Taklamakan Desert, China. Atmos. Environ., 38, 6927-6935, doi: 10.1016/j.atmosenv.2004. 03.078. [Link]

Predes, P., J. M. Andrade, P. L.-Mahía, and D. Prada, 1999: Source apportionment of inorganic ions in airborne urban particles from Coruña city (N.W. of Spain) using positive matrix factorization. Talanta, 49, 165-178, doi: 10.1016/ S0039-9140(98)00356-7. [Link]

Ren, Z., Q. Gao, and F. Su, 2003: The characteristics of atmospheric environment in Beijing and the effect from dust. Sci. Eng. China, 5, 49-56. (in Chinese)

Shi, Z., L. Shao, T. P. Jone, A. G. Whittaker, S. Lu, K. A. Bérubé, T. He, and R. J. Richards, 2003: Characterization of airborne individual particles collected in an urban area, a satellite city and a clean air area in Beijing, 2001. Atmos. Environ., 37, 4097-4108, doi: 10.1016/S1352-2310(03) 00531-4. [Link]

Sun, Y., G. Zhuang, H. Yuan, and X. Y. Zhang, 2004: The physic-chemical characteristics and its source analysis of the 2002 super dust storm in Beijing. Chin. Sci. Bull., 49, 291-298, doi: 10.1360/03wb0157.

Wang, M., J. W. Winchester, and S. Li, 1987: Aerosol composition in the drylands of northwestern China. Nucl. Instr. Meth. Phys. Res., 22, 275-282, doi: 10.1016/0168-583X (87)90342-9. [Link]

Wang, Y. Q., X. Y. Zhang, R. Arimoto, J. J. Cao, and Z. X. Shen, 2004: The transport pathways and sources of $\mathrm{PM}_{10}$ pollution in Beijing during spring 2001, 2002 and 2003. Geophys. Res. Lett., 31, L14110, doi: 10.1029/2004GL 019732. [Link]

Whittaker, A. G., T. P.Jones, L. Shao, Z. Shi, K. A. Bérubé, and R. J. Richards, 2003: Mineral dust in urban air: Beijing, China. Mineral. Mag., 67, 173-182, doi: 10.1180/0026 461036720111. [Link]

$\mathrm{Xu}, \mathrm{X} ., 1993$ : Research of Clay and Deposit in Saline Lakes in China, Science Publishing Company, 193 pp.

Yabuki, S., A. Okada, A. Ueda, Q. Chang, and Z. L. Fan, 1998: Sulfur isotope study of salt materials in saline lands and salt deposits around the desert areas in Xinjiang, China Implications to the study of the source of the aeolian dust of inland Asia. J. Arid Land Studies, 7, 127-138.

Yabuki, S., S. Kaneyama, F. G. Fu, M. Honda, F. Yanagisawa, W. S. Wei, F. J. Zeng, M. Z. Liu, Z. B. She, and L. Liu, 2002: Physical and chemical characteristics of Aeolian dust collected over Asian dust source regions in China Comparison with atmospheric aerosols in an urban area at Wako, Japan. J. Arid Land Studies, 11, 273-289.

Yang, Q., 1996: Asic sedimentary characters and paleoclimatic implications of saline lakes in Inner Mongolia. Geol. Chem. Miner., 18, 49-53. (in Chinese)

Yuan, C. S., C. X. Hai, and M. Zhao, 2006: Source profiles and fingerprints of fine and coarse sand resuspended from soils sampled in central Inner Mongolia. China Particuology, 4 
304-311, doi: 10.1016/S1672-2515(07)60280-2. [Link]

Yuan, H., Y. Wang, and G. Zhuang, 2003: The simultanious determination of organic acid, MSA with the inorganic anions in aerosol and rainwater by ion chromatograph. $J$. Instr. Anal., 22, 12-16. (in Chinese)

Yuan, H., K. A. Rahn, and G. Zhuang, 2004: Graphical techniques for interpreting the composition of individual aerosol particles. Atmos. Environ., 38, 6845-6854, doi: 10.1016/ j.atmosenv.2004.09.010. [Link]

Yuan, H., G. Zhuang, K. A. Rahn, X. Zhang, and Y. Li, 2006: Composition and mixing of individual particles in dust and nondust conditions of north China, spring 2002. J. Geophys. Res., 111, D20208, doi: 10.1029/2005JD006478. [Link]

Zhang, D., G. Shi, Y. Iwasaka, and M. Hu, 2000: Mixture of sulfate and nitrate in coastal atmospheric aerosols: Individual particle studies in Qingdao (36 $\left.04^{\prime} \mathrm{N}, 120^{\circ} 21^{\prime} \mathrm{E}\right)$, China. Atmos. Environ., 33, 3213-3223. [Link]

Zhang, D., J. Zang, G. Shi, Y. Iwasaka, A. Matsuki, and D. Trochkine, 2003: Mixture state of individual Asian dust particles at a coastal site of Qingdao, China. Atmos. Environ., 37, 3895-3901, doi: 10.1016/S1352-2310(03) 00506-5. [Link]

Zhang, K. and B. Zheng, 2003: The saline storm from ChaGanNuo'Er lake threatens the green Olympic Games in Beijing, http://www.sina.com.cn, 2003-10-07, 04:13.
Zhang, X. Y., R. Arimoto, and Z. S. An, 1997: Dust emission from Chinese desert sources linked to variations in atmospheric circulation. J. Geophys. Res., 102, 28041-28047, doi: 10.1029/97JD02300. [Link]

Zhang, X., S. Gong, Z. Shen, F. Mei, X. Xi, L. Liu, Z. Zhou, D. Wang, Y. Wang, and Y. Cheng, 2003: Characterization of soil dust aerosol in China and its transport and distribution during 2001 ACE-Asia: 1. Network observations. J. Geophys. Res., 108, ACH 3/1-ACH 3/13. [Link]

Zhang, X., G. Zhuang, J. Chen, and H. Xue, 2005: Speciation of the elements and compositions over the surfaces of dust storm particles. Chin. Sci. Bull., 50, 738-744.

Zhuang, G., Z. Yi, R. A. Duce, and P. R. Brown, 1992: Link between iron and sulfur suggested by the detection of $\mathrm{Fe}$ (11) in remote marine aerosols. Nature, 355, 537-539, doi: 10.1038/355537a0. [Link]

Zhuang, G., J. Guo, H. Yuan, and C. Zhao, 2001: The compositions, sources, and size distribution of the dust storm from China in spring of 2000 and its impact on the global environment. Chin. Sci. Bull., 46, 895-900, doi: 10.1007/BF 02900460. [Link]

Zhuang, G., J. Guo, H. Yuan, and X. Zhang, 2003: Coupling and feedback between iron and sulphur in air-sea exchange. Chin. Sci. Bull., 48, 1080-1086, doi: 10.1360/02wb0205. [Link] 